\title{
Voltage Stability Analysis of Wind Power Integrated System Based on Flexible HVDC Technology
}

\author{
Tianze Dai \\ School of Control and Computer Engineering Electrical Engineering and Automation, North China \\ Electric Power University, Beijing, 102206, China \\ email: savoryly@163.com
}

Keywords: Wind power; Voltage stability; DC transmission

\begin{abstract}
Regarding an isolated system in Huolinhe region as the object of study, in order to reduce the system voltage fluctuation and improve system voltage stability, the paper proposes that the wind farm uses the access way of flexible DC into system. The Flexible transmission mode bases the DC voltage source inverter on the directional characteristics and realizes the decoupling of active and reactive power with pulse width modulation technology, which can be adjusted independently and continuously.
\end{abstract}

\section{Introduction}

The uncontrolling of output of wind turbines in wind power has a series of bad impact on the grid, where the problem of voltage stability in the wind farm grid system is particularly prominent.

The flexible HVDC technology uses pulse width modulation, by controlling strategies it is possible to adjust the output of reactive power, carry out the reactive power compensation on the wind farm and strengthen the reliability and stability of the power grid.

The document [1-2] describes the working principle and modulation mode of voltage source converter; in the document [3] the specific application of flexible HVDC technology is introduced ,and we also analyses its great contribution to the city power grid; the document [4-5] briefly introduce the adverse effects brought by large-scale wind power integration. In this paper, the access mode of wind power plant to system by flexible HVDC technology is studied. Based on an isolated system, flexible DC technology was studied as a supporting role in static voltage stability and the influence of integrated wind farm capacity on the system stability are under consideration as well.

\section{The construction and control principle of system}

\section{The basic construction of system}

The flexible HVDC system mainly includes the DC converter and DC transmission lines. In the wind farm integration system based on the technology of flexible DC, sending end converter station can be running as a rectifier station, and receiving end converter station can be running as inverter station. What connect two converter stations are two DC lines, it has the capability of the power exchange and the transmission of the active trend between the converter stations [1]. The main equipment of flexible HVDC system generally include: coupling transformer, AC filter, phase reactor, voltage source inverter, DC capacitance, DC transmission lines, protection and the control of auxiliary system (water cooling system, station power system), etc.

\section{Decoupling control of active power/reactive power at point of integration}

The voltage source inverter is applied to the flexible HVDC system, whose bridge arms are made up of high power controlled shut-off device(like IGBT、IGCT) and the parallel diode[2],it can be shut off many times for commutation within a cycle. PWM modulation technology is used to control the trigger of valve so that the voltage source inverter can output similar sine wave. Under the function of control system, the voltage source inverter output amplitude of voltage fundamental component and phase Angle that can be altered independently. Which makes it 
possible to continuous independently regulate active and reactive power.

Refer to phase of AC side voltage, AC side of voltage source inverter output the fundamental component of voltage $\left(U_{c}\right)$ is as follows:

$$
U_{c}=\frac{\mu M}{\sqrt{2}} u_{d} \angle \delta_{s}-\delta
$$

In this: $\mu$ for DC voltage utilization; $u_{d}$ for the DC side voltage of voltage source inverter; $\mathrm{M}$ for the modulation ratio (i.e. the ratio of output ac voltage and the DC voltage of inverter); $\delta$ for phase Angle difference between AC busbar voltage and voltage source inverter output voltage; $\delta_{s}$ for the grid AC bus voltage phase Angle.

Under condition of not considering the resistance of the coupling transformer and reactor and ignoring the harmonic component, the exchanging active power and reactive power between the inverter and the alternating current system are as follows[3]:

$$
\begin{gathered}
\mathrm{P}=-\frac{U_{S} U_{c}}{x} \sin \delta \\
\mathrm{Q}=\frac{U_{S}\left(U_{S}-U_{c} \cos \delta\right)}{x}
\end{gathered}
$$

In this: $U_{s}$ for busbar voltage of the grid AC system; x for reactance of bridge arm electric reactor of the inverter.

From the above equation we know that it is possible to independently regulate the exchanging active power and reactive power between inverter and AC system by controlling $\mathrm{M}$ and $\delta$ with PWM technology.

\section{Analysis of voltage stability of wind power in the flexible DC integration system}

\section{The overview of the simulation grid}

In this paper PSS/E was carried out on the simulation analysis of the grid. Within an isolated power grid a given area wind farm was connected to the grid by flexible HVDC technology. The grid consists of 6 substations of 220KV, 2 substations of $110 \mathrm{KV}$,in which there are 9 main transformer of $220 \mathrm{KV}, 5$ main transformer of $110 \mathrm{KV}$; The grid also consists of 12 lines of $220 \mathrm{KV}, 3$ lines of $110 \mathrm{KV}$ and 3 wind farms. And $1 \#$ wind farm of $200 \mathrm{MW}$ is accessing power grid by way of flexible HVDC, 2\# wind farm of 200MW is accessing wind power stations of $220 \mathrm{KV}$ through two-leveled rising voltage of $690 \mathrm{~V} / 35 \mathrm{KV}$ and $35 \mathrm{KV} / 220 \mathrm{KV}$.All the wind motor that equipped with direct drive wind turbines can make the wind generator working at their best efficiency, its speed has nothing to do with AC power grid frequency. In summer of 2012 the expected maximum load is 1400MW.

The flexible HVDC system sending converter station uses the active power control strategy of slope characteristics, allowing wind farm frequency change along with active power within a certain range, the control strategy of reactive power and voltage is: within the allowing scope of the grid guideline it controls the integration node voltage dynamically with differential slope adjustment.

The control mode of the converter station of the flexible HVDC system is as follows: active power that adopts direct current voltage control can make the whole DC power system real-time balanced. The input direct current network active power must be equal to the DC network output active power and power loss of DC network and converter bridge[4]. Reactive power control uses reactive power control mode and the ending side of running voltage is stabilized in real time.

\section{Support analysis for stability of static voltage}

In operation of steady state, with the increase of output active power the fan, sending side of the inverter's output active power and absorbed reactive power also increases accordingly. In the grid absorpted reactive power of wind farms will increase and thus node voltage drops. As a consequence, the fan low voltage protection starts. It makes the fan run out and causes failure[5].By the way of changing the inverter AC side's output voltage of the fundamental component $\mathrm{Uc},\left(\mathrm{U}_{\mathrm{s}}-\mathrm{U}_{\mathrm{c}} \cos \delta\right)<0$.Sending end of voltage source inverter issues reactive power and provide integration node of wind farm with reactive power support so that integration node's voltage can keep stable.

The researchers analyze the static flow of the grid at system simulation platform, with the 
increase of the wind power plant output, main load node voltage's amplitude (standard) changes as shown as figure 1 under 4 kinds of wind power integration mode.

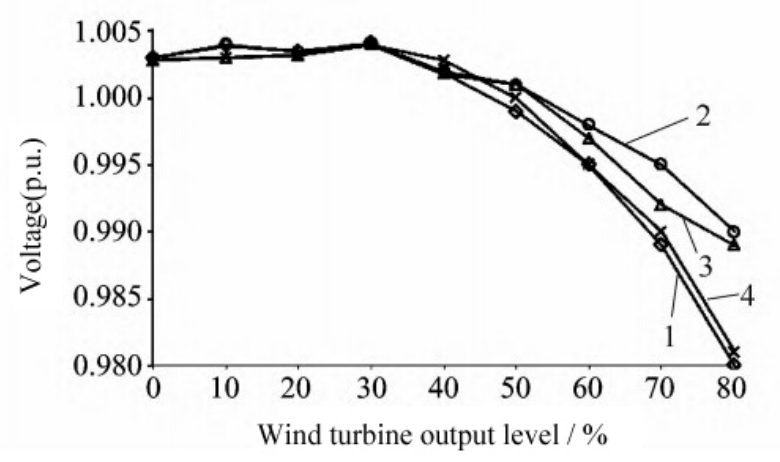

Fig.1.Bus voltage curve of aluminum load node

1) Way 1: Curve 1 represents the change of load node voltage when the wind farm are connected to the grid in AC mode.

2) Way 2: Curve 2 represents the change of busbar voltage of load node when wind farm 1 is connected to the grid with the way of flexible DC and the other two wind farms are connected to the grid with the way of alternating current.

3) Way 3: The access of wind farm that described in curve 3 is the same as the above curve 2, the wind farm capacity for access are $400 \mathrm{MW}, 400 \mathrm{MW}, 800 \mathrm{MW}$ in order.

4) Way 4: The access of wind farm that described in curve 4 is the same as the above curve 2, the wind farm capacity for access are $400 \mathrm{MW}, 400 \mathrm{MW}, 800 \mathrm{MW}$ in order.

To sum up, when the wind power integration capacity accounts for $50 \%$ of the total capacity of generator, it is effective to cope with negative influence on voltage of the system that brought by large-scale wind power integration into the grid. When the wind power integration capacity of generator occupies over $50 \%$ of the total capacity, it is hard to maintain the stability of system voltage even with using the flexible DC integration method; it needs to add additional reactive power compensator.

\section{Analysis of stability of transient voltage}

\section{Unit failure}

Three-phase short-circuit fault of generators occur at 0 second in the conventional generating set that connected to the bus 3 , then at 0.5 second the unit is removed .The simulation curve of unit's angle, system frequency an load node voltage in the whole process are as shown in figure2 4.

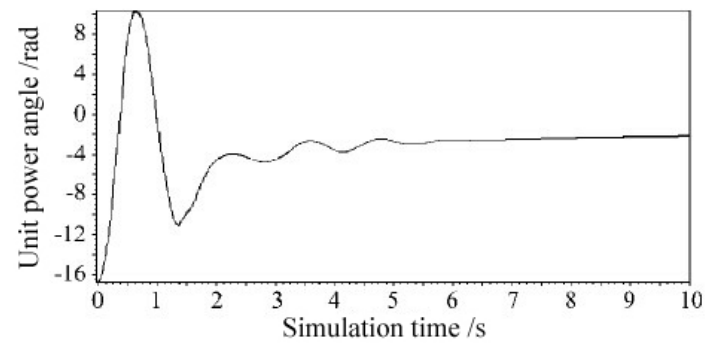

Fig.2. Unit power angle curve (unit failure)

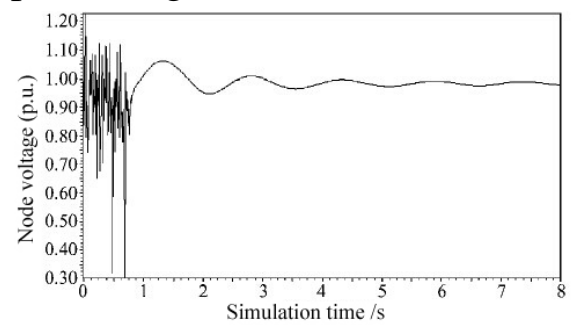

Fig.4.Load node voltage curve (unit failure)

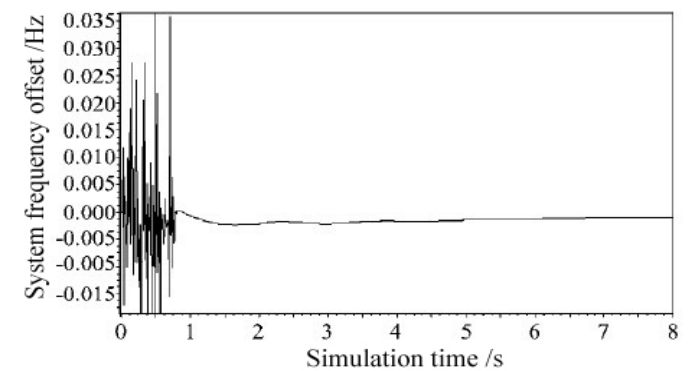

Fig.3.System frequency curve (unit failure)

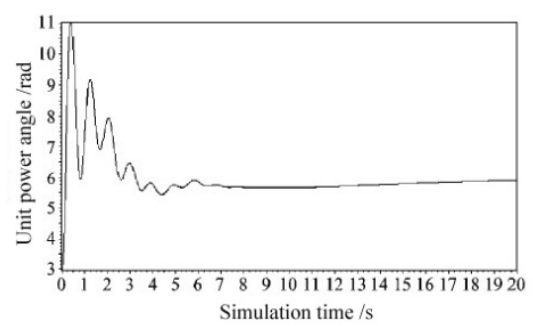

Fig.5.Unit power angle curve (Load failure) 
The capacity of the conventional power generation unit is huge, when system lost balance because of its lack of a lot of active power after failure, it needs the other conventional units and wind turbine to give out more active power. Wind farms do not cause the lack of reactive power and instability of voltage while in the provision of a large number of active power because of the adoption of the flexible HVDC. It can be seen from the figure 5, the system voltage quickly recover after severe disturbance without security measures.

\section{The fault of load}

A load in aluminum manufacturer break down and is removed at 0second, the simulation curve of the angle, system frequency and load node voltage in the whole process that describe the above phenomena is as shown in figure $5 \sim 7$.
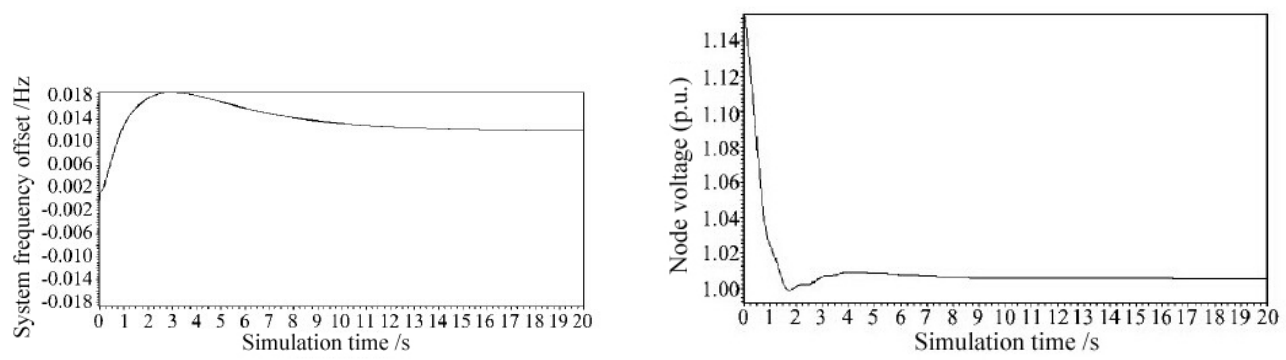

Fig.6.System frequency curve (Load failure) Fig.7.Load node voltage curve (Load failure)

The wind generators does not appear large voltage fluctuations at the same time of reducing output of active power because of using the flexible direct current transmission way. The voltage change smoothly and can restore to stable without safe measures after the disturbance.

\section{Conclusion}

In this paper by using the simulation software PSS/E, we make a research about the isolated power grid simulation on system static stability of voltage, transient stability and voltage supporting ability .Through the way of comparing the analysis of the different methods of communication and flexible HVDC simulation results, it is further demonstrated that the flexible DC technology play a beneficial role on wind power integration system.

\section{References}

[1] HU Hao. Expectation of the Application Prospects of the Flexible HVDC Transmission Technology in China[J]. East China Electric Power, 2011,39(9):1509-1510

[2] XU Zheng, CHEN Hairong. Review and Applications of VSC HVDC[J].High voltage engineering,2007,31(1):2.

[3] LI Yin-hui, YANG Jing-yan, ZHANG Jian-hua, LI Sheng, ZHOU Ming-xia. Application of VSC-HVDC in Urban High Voltage Power Network[J].Power System and Clean Energy, 2009,25(8): 15-17

[4] ZHU Yi-fan. Application of Flexible HVDC Transmission Technology in Grid-connected Wind Power[J]. East China Electric Power, 2011, 39(7):1132-1133.

[5] FRANQUELO L G, RODRIGUEZ J, LEON J I, et al. The Age of Multilevel Converters Arrives[J]. IEEE Industrial Electronics Magazine, 2008, 2(2): 35-39. 